\title{
What is the optimal dose of botulinum toxin A in the treatment of cervical dystonia? Results of a double blind, placebo controlled, dose ranging study using Dysport ${ }^{\circledR}$
}

W Poewe, G Deuschl, A Nebe, E Feifel, J Wissel, R Benecke, K R Kessler, A O Ceballos-Baumann, A Ohly, W Oertel, G Künig, for the German Dystonia Study Group (GDSG)

\begin{tabular}{|c|}
\hline $\begin{array}{l}\text { Department of } \\
\text { Neurology, University } \\
\text { of Berlin } \\
\text { W Poewe } \\
\text { A Nebe } \\
\text { J Wissel }\end{array}$ \\
\hline
\end{tabular}

Department of Neurology, University of Dusseldorf

R Benecke

K R Kessler

Department of Neurology, University of Freiburg

G Deuschl

E Feifel

Department of Neurology, University of Kiel

G Deuschl

Department of Neurology, University of LMU-München

W Oertel

G Künig

Department of Neurology, University of TU-Munchen A O Ceballos-Baumann A Ohly

Department of Neurology, University of Marburg W Oertel

Department of Neurology, University of Rostock

$\mathrm{R}$ Benecke

Department of Neurology, Universitat Innsbruck, Austria W Poewe

Correspondence to: Professor G Deuschl, Neurologische Klinik der Christian-Albrechts-Universität, Niemannsweg 147, D-24105 Kiel, Germany. Telephone 0049431597 2610; fax 00494315972712 .

Received 6 November 1996 and in revised form 2 June 1997

Accepted 18 June 1997

\begin{abstract}
Objectives-Botulinum toxin injections have become a first line therapeutic approach in cervical dystonia. Nevertheless, published dosing schedules, responder rates, and frequency of adverse events vary widely. The present prospective multicentre placebo controlled double blind dose ranging study was performed in a homogenous group of previously untreated patients with rotational torticollis to obtain objective data on doseresponse relations.
\end{abstract}

Methods-Seventy five patients were randomly assigned to receive treatment with placebo or total doses of 250,500 , and 1000 Dysport ${ }^{\circledR}$ units divided between one splenius capitis $(0,175,350,700$ units) and the contralateral sternocleidomastoid $(0,75$, 150, 300 units) muscle. Assessments were obtained at baseline and weeks 2,4 , and 8 after treatment and comprised a modified Tsui scale, a four point pain scale, a checklist of adverse events, global assessment of improvement, and a global rating taking into account efficacy and adverse events. At week 8 the need for retreatment was assessed and then the code was unblinded. For those still responding, there was an open follow up until retreatment to assess the duration of effect.

Results-seventy nine per cent reported subjective improvement at one or more follow up visits. Decreases in the modified Tsui score were significant at week 4 for the 500 and 1000 unit groups versus placebo $(p<0.05)$. Additionally positive dose-response relations were found for the degree of subjective improvement, duration of improvement, improvement on clinical global rating, and need for reinjection at eight weeks. A significant dose relation was also established for the number of adverse events overall and for the incidence of neck muscle weakness and voice changes.

Conclusion-Magnitude and duration of improvement was greatest after injections of 1000 units Dysport ${ }^{\circledR}$; however, at the cost of significantly more adverse events. Therefore a lower starting dose of $\mathbf{5 0 0}$ units Dysport ${ }^{\circledR}$ is recommended in patients with cervical dystonia, with upward titration at subsequent injection sessions if clinically necessary.

(F Neurol Neurosurg Psychiatry 1998;64:13-17)

Keywords: botulinum toxin A; cervical dystonia; dose range

Cervical dystonia is a common form of focal dystonia with an estimated prevalence of at least $8 / 100000 .^{1}$ Medical treatment of the condition has generally been unsatisfactory. Over the past 10 years local injection of botulinum toxin into various neck muscles has become the first line therapeutic approach and published data from controlled and uncontrolled clinical studies now cover many thousands of treatment sessions in hundreds of patients. ${ }^{2-18}$ Responder rates vary widely between $20 \%$ and $75 \%$ based on variable assessment methods and variable doses used and most of the clinical information comes from open label trials. ${ }^{11-18}$ There continues to be considerable uncertainty about optimal doses of botulinum toxin type A for the treatment of cervical dystonia. The issue is further complicated by the fact that the assays used to determine the mouse units which describe the potency of the two currently available commercial preparations of botulinum toxin type A are not equivalent. The present placebo controlled double blind prospective study was performed to obtain objective information on doseresponse relations of one botulinum toxin preparation (Dysport ${ }^{\circledR}$ ) in a homogenous group of previously untreated patients with cervical dystonia (rotational torticollis).

\section{Patients and methods}

PATIENTS

Seventy five patients (39 men, 36 women) aged between 26-82 (mean 47 (SD 11.5)) years with rotational torticollis and hyperactivity clinically confined to one splenius capitis and the contralateral sternomastoid muscles, who were previously untreated with botulinum toxin type A were included in the study. Patients were continously and prospectively recruited from routine referrals to the dystonia clinics of the participating centres. Patterns of dystonic muscle involvement were identified on clinical grounds (direction of head deviation, visible hypertrophy, and palpable stiffness as well as localisation of pain). Disease 
Table 1 Blinded study medication: vial composition

\begin{tabular}{lll}
\hline \multirow{2}{*}{$\begin{array}{l}\text { Treatment } \\
\text { group }\end{array}$} & \multicolumn{2}{c}{ Number of vials } \\
\cline { 2 - 3 } & Active & Placebo \\
\hline Placebo & 0 & 2.5 \\
250 units & 0.5 & 2 \\
500 units & 1 & 1.5 \\
1000 units & 2 & 0.5 \\
\hline
\end{tabular}

Units=units of Dysport ${ }^{\circledR}$. duration ranged from one month to 30 years (mean 7.38 (SD 6.74) years). Ten patients also had dystonia at other sites, including writer's cramp (four patients) and Meige's syndrome (three patients). Nineteen patients were receiving one or more drugs for the treatment of their torticollis (benzodiazepine drugs in 12 patients, anticholinergic drugs in five patients). For the duration of the study the drug regimen was kept constant except for the possible introduction of diclofenac, if required, for the relief of pain associated with the torticollis. Duration and dosage of diclofenac were recorded for subsequent evaluation.

\section{METHODS}

Patients were randomly assigned to receive treatment with placebo or total doses of 250, 500 , or 1000 Dysport ${ }^{\circledR}$ units of botulinum toxin type $\mathrm{A}$ in a double blind prospective study design. These doses were chosen as they represent the lower and upper ends of the range of empirically defined injection protocols.

As Dysport ${ }^{\circledR}$ is only manufactured in vials containing 500 units, the only way to blind the study was to supply the study medication for each patient in three individual vials. The vials were labelled A, B, and C and patients received the full contents of vials $A$ and $B$. but only half the contents of vial C. Each vial contained either active botulinum toxin type A (500 units Dysport ${ }^{\circledR}$ together with $125 \mu \mathrm{g}$ human albumin and $2.5 \mathrm{mg}$ lactose) or matching placebo. All three vials were identical in appearance and were reconstituted with $1 \mathrm{ml}$ normal saline. The number of active vials received by the patients was determined by the treatment group to which they had been allocated (table 1).

For treatment $1 \mathrm{ml}$ was drawn from vials A and $B$ and $0.5 \mathrm{ml}$ from vial $C$. Of this $2.5 \mathrm{ml}$ solution, $0.75 \mathrm{ml}$ was injected in equal proportions into two sides $1 \mathrm{~cm}$ apart in the upper one third of the sternomastoid muscle contralateral to the direction of chin rotation (corresponding to $0,75,150$, and 300 units Dysport ${ }^{\circledR}$ for the various treatment groups), and $1.75 \mathrm{ml}$ were divided between two injection sides in the splenius capitis muscle (corresponding to 0,175 , 350, and 700 units Dysport ${ }^{\circledR}$ ) ipsilateral to the direction of head turn according to a previously described injection technique. ${ }^{11}{ }^{19}$ Because of easy clinical identification of these two neck muscles injections were not guided by EMG.

The following assessments were made at baseline and weeks 2,4 , and 8 after treatment for all patients:

- Rating of postural head deviation using a modification of the scale originally published by Tsui et al $1986 .^{2}$ To increase the sensitivity of the scale the ratings for postural head deviation were performed for four different modes of postural activation (sitting, lying, standing, walking) at each visit (see appendix)

- Rating of torticollis associated pain on a four point scale (absent, mild, moderate, severe)

- Swallowing difficulties for both liquids and solids using a five point scale (no difficulty, mild difficulty, moderate difficulty, severe problems, swallowing not possible).

In addition the following items were assessed during each follow up visit:

- Global assessment of postinjection improvement over baseline by both patient and physician on a five point scale (worse than baseline, no improvement, improvement $<50 \%$, improvement $>50 \%$, and complete remission)

- A checklist of specific adverse events that have been associated with botulinum toxin treatment was scored as none, mild, moderate, or severe.

- A clinical global rating taking into account efficacy and adverse events was assigned at week 8 (efficacy: excellent, good, moderate, slight improvement, no change, condition worse; safety: none, mild, moderate, extreme)

- Need for retreatment at week 8 .

At week 8 the blind was broken allowing open follow up until retreatment, for those still responding, to assess the duration of effect.

\section{STATISTICAL ANALYSIS}

As the study was conducted on a multicentre design, homogeneity tests were carried out for age, sex, and duration and severity of torticollis. Between group comparisons were evaluated by means of the Kruskall-Wallis analysis and changes in the modified Tsui score were also assessed with the Maentel-Haenszel test.

\section{Results}

Overall, the groups were well matched for age, sex, height, weight, duration of symptoms, and severity of torticollis. One patient in the 500 unit group was lost for follow up and had to be excluded from results analysis. A further case of the 500 unit group had missed one follow up visit and was excluded from efficacy analysis but included in analysis of adverse events. Fifty eight of the 73 patients (79\%) treated reported subjective improvement at one or more follow up visits. The physicians' global assessment recorded 60 patients $(81 \%)$ as improved over baseline. Detailed analysis of the various response indices in the different groups gave the following results.

\section{POSTURAL DEVIATION}

At baseline patient groups were well matched for severity of their modified Tsui scores for postural head deviation $(14.4,14.3,13.1$ and 14.5 points for placebo, 250, 500, and 1000 unit groups respectively). After injections, clinically meaningful score reduction only occurred in the three active treatment groups. This improvement was evident by week 2 in all active groups, and peak effects with significant score reduction were noted at week 4 for the 500 and 1000 unit groups (fig 1).

The percentage of patients reporting $>50 \%$ subjective improvement was around $10 \%$ for both the placebo and 250 unit group at all follow up visits. There was a dose dependent and significant increase in this percentage for the 500 and 1000 unit groups at week 4 and week 8 (fig 2) rising to $50 \%$ of patients in the 1000 unit treatment group. 


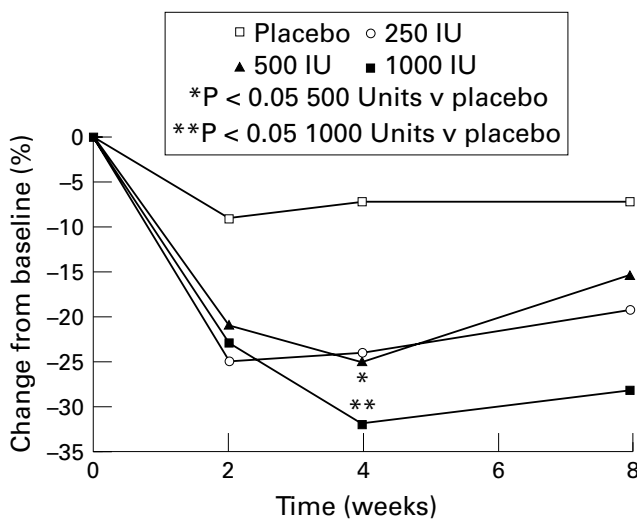

Figure 1 Mean modified Tsui score of patients in the different treatment groups. Score reduction is expressed as percentages of change from baseline mean modified Tsui score.

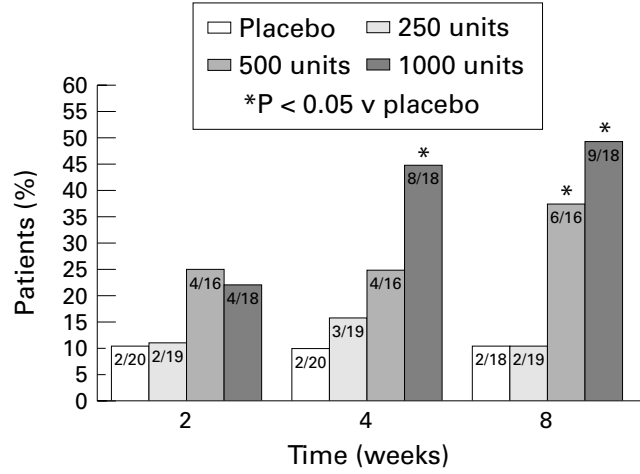

Figure 2 Percentages (numbers) of patients in the different treatment groups experiencing $>50 \%$ global subjective improvement.

LATENCY AND DURATION OF EFFECT

Whereas the mean latency to onset of clinical benefit was found to be 8 and 9 days for all active groups, the duration of effect seemed to be dose dependent (fig 1). The persisting decrease in modified Tsui scores by week 8 was greater in the 1000 compared with the 250 and 500 unit groups although this difference failed to reach significance.

Another indication for a longer duration of effect in the highest dose group is reflected by the number of patients requesting reinjection at eight weeks because of insufficient maintained response. Ninety four per cent of the patients treated with placebo requested another injection at eight weeks. In the groups treated with 250 and 500 units about half of the patients requested reinjection whereas only $39 \%$ of the patients in the 1000 unit group required retreatment at week 8 .

PAIN

Only 31 of the 75 patients ( $41 \%$ ) had moderate to severe neck and shoulder pain related to torticollis and these patients were unevenly distributed across the four treatment groups $(29 \%, 35.5 \%, 19.4 \%$, and $16.1 \%$ in the placebo, 250, 500, and 1000 unit groups respectively). After injection there was an improvement in all treatment groups with a clear difference between placebo and active groups by week 4 , but there was no doseresponse relation within the active groups. Fif- teen per cent of patients took diclofenac to treat pain associated with torticollis (two patients in the placebo group, three in the 250 unit group, five in the 500 unit group, and one in the 1000 unit group).

\section{ADVERSE EVENTS}

Using a check list at each visit to ensure full recording of adverse events, a clearly significant dose relation was established for the number of events overall and for the incidence of neck muscle weakness and voice changes. Most events were mild and transient, lasting for one to four weeks. Relative frequencies of adverse event reporting were $25 \%, 37 \%, 65 \%$, and $83 \%$ for placebo, 250, 500, and 1000 unit groups respectively (table 2 ). There was a significant difference between the incidence of adverse events in the 1000 unit group and placebo group $(\mathrm{p}=0.004)$ and between the 1000 unit group and 250 unit group $(p=0.05)$. Neck weakness was noted significantly more often in the 1000 unit group than any other group, whereas voice changes were noted significantly more often in the 1000 unit group than placebo or 250 unit groups. There was no significant difference between groups with respect to dysphagia, although it was the most often reported event. Numerically, the highest number of reports of swallowing problems were in the 1000 unit group (table 2) and analysis of the severity of dysphagia also supports a dose response effect, with more severe episodes of dysphagia associated with higher doses (table 3), but absolute numbers of patients in the different treatment groups may have been too small to detect significant differences.

\section{CLINICAL GLOBAL RATING}

At week 8 clinical global rating assessed efficacy and adverse events together. Moderate to excellent efficacy associated with none to moderate adverse events was considered optimal. Optimal responses were noted by 13 of 18 $(72 \%)$ of the 1000 unit group, seven of 16 (44\%) of the 500 unit group, seven of $19(39 \%)$ of the 250 unit group, and two of $20(10 \%)$ of the placebo group.

\section{Discussion}

Although local injection of botulinum toxin A into neck muscles is now a first line treatment approach in patients with cervical dystonia, dosing schedules are largely based on uncontrolled clinical experience in diverse populations and thus vary considerably between centres even when the same toxin preparation is used. ${ }^{19}$ The present trial is the first to supply information on those response relations using a prospective double blind placebo controlled design in a carefully controlled homogenous group of previously untreated patients with rotational torticollis.

Retrospective analysis of previously published studies failed to show a clear dose response relation for either preparation of toxin. ${ }^{19}$ This includes findings from double blind studies in which Tsui et $a l^{2}$ using total doses of 100 units Botox ${ }^{\circledR}$, were able to produce a $63 \%$ response rate, and two studies 
Table 2 Adverse events ( $(\%))$

\begin{tabular}{|c|c|c|c|c|c|}
\hline Adverse events & $\begin{array}{c}\text { Placebo } \\
(n=20)\end{array}$ & $\begin{array}{l}250 \text { units } \\
(n=19)\end{array}$ & $\begin{array}{l}500 \text { units } \\
(n=17)\end{array}$ & $\begin{array}{l}1000 \text { units } \\
(n=18)\end{array}$ & All groups (74) \\
\hline Patients with adverse events & $5(25)$ & $7(37)$ & $11(65)$ & $15(83)^{\star}$ & $37(50)$ \\
\hline Adverse events & 7 & 16 & 24 & 47 & 94 \\
\hline Dysphagia/swallowing problems (n (\%)) & $2(10)$ & $4(21)$ & $5(29)$ & $7(39)$ & $18(24)$ \\
\hline Neck weakness & 0 & $2(11)$ & $2(12)$ & $10(56)^{\star \star}$ & $14(19)$ \\
\hline Dry mouth & $1(5)$ & $4(21)$ & $3(18)$ & $6(33)$ & $14(19)$ \\
\hline Discomfort at injection site & $2(10)$ & $1(5)$ & $3(18)$ & $5(28)$ & $11(15)$ \\
\hline Tiredness & $1(5)$ & $3(16)$ & $2(12)$ & $3(17)$ & $9(12)$ \\
\hline Voice change/hoarseness & 0 & 0 & $3(18)$ & $5(28)^{\star}$ & $8(11)$ \\
\hline Visual difficulty/blurring & 0 & 0 & $1(6)$ & $3(17)$ & $4(5)$ \\
\hline Jaw weakness & 0 & $1(5)$ & 0 & $2(11)$ & $3(4)$ \\
\hline Vertigo/dizziness & 0 & 0 & $1(6)$ & $2(11)$ & $3(4)$ \\
\hline Respiratory difficulty & 0 & 0 & 0 & $1(6)$ & $1(1)$ \\
\hline Respiratory infection & 0 & 0 & 0 & $1(6)$ & $1(1)$ \\
\hline Fever & 0 & 0 & 0 & $1(6)$ & $1(1)$ \\
\hline Diarrhoea & 0 & 0 & 0 & $1(6)$ & $1(1)$ \\
\hline Headache & 0 & 0 & $1(6)$ & 0 & $1(1)$ \\
\hline Concentration problem & 0 & 0 & $1(6)$ & 0 & $1(1)$ \\
\hline Feel mad & 0 & 0 & $1(6)$ & 0 & $1(1)$ \\
\hline Itching & 0 & 0 & $1(6)$ & 0 & $1(1)$ \\
\hline Increased sweating & 0 & $1(5)$ & 0 & 0 & $1(1)$ \\
\hline Nausea/vertigo & $1(5)$ & 0 & 0 & 0 & $1(1)$ \\
\hline
\end{tabular}

$\star$ Significant difference from placebo and 250 unit arms; ${ }^{\star \star}$ significant difference from placebo, 250 , and 500 unit arms.

Units=units of Dysport ${ }^{\circledR}$.

Table 3 Severity of dysphagia

\begin{tabular}{lllll}
\hline Severity & Placebo & 250 units & 500 units & 1000 units \\
\hline Mild & 2 & 4 & 3 & 4 \\
Moderate & 0 & 0 & 2 & 2 \\
Severe & 0 & 0 & 0 & 1 \\
Total (n) & 2 & 4 & 5 & 7 \\
\hline
\end{tabular}

Units=units of Dysport ${ }^{\circledR}$

by Gelb et $a l^{8}$ who found responder rates between $15 \%$ and $32 \%$ using 280 units Botox ${ }^{\circledR}$. More relevant to the present study, all but one study ${ }^{18}$ using injections of 500-1200 units Dysport ${ }^{\circledR}$ for cervical dystonia have produced response rates of at least $70 \%$, again without a clear dose response relation (see Poewe and Wissel ${ }^{19}$ for review). Based on these experiences it might have been expected that 500 units Dysport ${ }^{\circledR}$ would benefit at least two thirds of all patients with cervical dystonia so treated, with information about the possible efficacy of still lower doses lacking. In the present study particular emphasis was placed on homogeneous patterns of dystonic muscle involvement across all treatment groups. It clearly shows that there is a positive relation between the degree of improvement as judged by the reduction of modified Tsui scores and the dose of Dysport ${ }^{\circledR}$ injected. Whereas all doses produced at least $20 \%$ score reductions compared with baseline by two weeks after treatment such changes remained robust over eight weeks only for the 1000 unit group. Subjective response ratings confirmed this relation between total dose and degree of improvement as patients receiving 500 or 1000 units experienced a greater than $50 \%$ global subjective improvement significantly more often than patients treated with placebo or 250 units.

A second, maybe more important, finding from the present study is that there also seems to be a positive relation between dose injected and the duration of clinical benefit. Ninety four per cent of patients treated with placebo and about $50 \%$ of patients receiving 200 and 500 units requested reinjection by eight weeks whereas only $39 \%$ of those having received
1000 units asked for a second treatment by this time. This was in line with the prolonged reduction of modified Tsui scores in the last group. To our knowledge previous studies have failed to find a relation between dose of botulinum toxin injected and duration of clinical benefit. Nevertheless, such a correlation seems biologically plausible as recurrence of symptoms after botulinum toxin treatment of focal dystonia is thought to be related to reinnervation and thus may require more time with more extensive denervation after higher doses. ${ }^{20}$

Whereas there was some reduction in the numbers of patients reporting moderate or severe pain in all active groups during the entire follow up this did not seem to be related to total dose. However, there were fewer patients with pain in the high dose groups compared with placebo and the 250 unit group, which might have obscured possible dose responses.

There has been a tendency towards lower doses over the years, especially in European studies, to decrease the incidence of side effects. ${ }^{5} 1618$ This dose ranging study confirms the suspected correlation between the numbers of patients experiencing adverse effects and the total dose injected. Dysphagia was the commonest adverse event overall, but there was no significant difference in the incidence of dysphagia across the treatment groups. Numerically, the highest incidence of $39 \%$ was noted in the 1000 unit group but $10 \%$ incidence of dysphagia was also noted in the placebo group and may indicate an underlying condition. ${ }^{21}$ Only two adverse events were reported significantly more often in the 1000 unit group compared with placebo and the 250 unit group and this was neck muscle weakness experienced by $56 \%$ of all patients receiving 1000 units and voice changes or hoarseness reported by $28 \%$. Therefore, it seems that the major contribution to increased numbers of adverse events with high dose treatment comes from neck muscle weakness rather than from increased dysphagia. ${ }^{22}{ }^{23}$ Although the results of this study are only applicable to one particular botulinum 
toxin preparation they provide useful clinical information, confirming previous anecdotal clinical impressions. Using the Dysport ${ }^{\circledR}$ ) preparation of botulinum toxin in our patients there was some subjective improvement with the 250 units total dose and significant clinical effects were noticed only with doses of 500 and 1000 units. The biggest change over placebo with persistence of effect beyond two months was found for the 1000 unit group; however, at the cost of significantly more adverse events, particularly neck weakness. Based on the clinical global rating those effects were, however, tolerable in most cases with $72 \%$ of patients in the 1000 unit group considered as having an optimal response. From the present data we conclude that the effective dose range for botulinum toxin type A (Dysport ${ }^{\circledR}$ ) for torticollis is between 250 and 1000 units. To minimise the incidence of side effects we would recommend a starting dose of 500 units Dysport ${ }^{\circledR}$ in these patients which can then be titrated according to efficacy and sensitivity of the patient.

This work was supported by BMBF No OlKL9201/8. Toxin and placebo preparation was supplied by Speywood Pharmaceuticals Ltd. We acknowledge H Cohen (Speywood) for analyses and manuscript support.

\section{Appendix}

MODIFIED TSUI SCORE

(A) Amplitude of sustained movements: rotation, tilt, and anteroposterior deviation of the head were scored individually as $0=$ absent, $\mathrm{I}=<15^{\circ}, 2=15^{\circ}-30^{\circ}, 3=>30^{\circ}$. The three scores were summed together and assessed during lying (A1), sitting (A2), standing (A3), and walking (A4).

(C) Shoulder elevation rated at worst position $0=$ absent, $1=$ mild and intermittent, $2=$ mild and constant, $3=$ constant and severe.

(D) Head tremor rated at worst position: severity ( $1=$ mild, $2=$ severe $)$ was multiplied by duration $(1=$ occasional, $2=$ continous $)$.

Total score $=\mathrm{A} 1+\mathrm{A} 2+\mathrm{A} 3+\mathrm{A} 4+\mathrm{C}+\mathrm{D}$

1 Nutt JG, Muenter MD, Aronson A, Kurland LT, Melton LJ. Epidemiology of focal and generalized dystonia in Rochester, Minnesota. Mov Disord 1988;3:188-94.

2 Tsui JKC, Eisen A, Stoessel AJ, Calne S. Double blind study of botulinum toxin in spasmodic torticollis. Lancet 1986;11:245-6.
3 Gelb DJ, Lowenstein DH, Aminoff M. Controlled trial of botulinum toxin injections in the treatment of spasmodic torticollis. Neurology 1989;39:80-4.

4 Lorentz IT, Shanti Subramaniam S, Yiannikas C. Treatment of idiopathic spasmodic torticollis with botulinum toxin A: a double blind study on 23 patients. Mov Disord 1991;6:145-50.

5 Blackie JD, Lees AJ. Botulinum toxin treatment in spasmodic torticollis. F Neurol Neurosurg Psychiatry 1990; 53:640-3.

6 Greene P, Kang U, Fahn S, Brin M, Moskowitz C, Flaster E. Double blind, placebo-controlled trial of botulinum toxin injections for the treatment of spasmodic torticollis. Neurology 1990;40:1213-8.

7 Perlmutter JS, Tempel LW, Burde R. Double-blind, placebo-controlled, crossover trial of botulinum A toxin for torticollis. Neurology 1989;39:352.

8 Gelb DJ, Yoshimura DM, Olney RK, Lowenstein DH, Aminoff MJ. Change in pattern of muscle activity following botulinum toxin injections for torticollis. Ann Neurol 1991; 29:370-6.

9 Moore AP, Blumhardt LD. A double blind trial of botulinum toxin $\mathrm{A}$ in torticollis, with one year follow up. $\mathcal{7}$ Neurol Neurosurg Psychiatry 1991;34:813-6.

10 Tsui JK, Eisen A, Calne DB. Botulinum toxin in spasmodic torticollis. Adv Neurol 1988;50:593-7.

11 Poewe W, Schelosky L, Kleedorfer B. Treatment of spasmodic torticollis with local injection of botulinum toxin - one year follow up in 37 patients. F Neurol 1992;1: 21-6.

12 Jankovic J, Schwartz K, Donovan DT. Botulinum toxin treatment of cranial-cervical dystonia, spasmodic dysphonia, other focal dystonias and hemifacial spasm. $\mathcal{F}$ Neurol Neurosurg Psychiatry 1990;50:633-9.

13 Jankovic J, Schwartz K. Botulinum toxin treatment for cervical dystonia. Neurology 1990;40:277-80.

14 Brin MF, Fahn S, Moskowitz C, Friedman A, Shale HM, Greene P, Blitzer A. Localized injections of botulinum toxin for the treatment of focal dystonia and hemifacial spasm. Mov Diord 1987;2:237-54.

15 Wissel J, Poewe W. Dystonia - a clinical, neuropathological and therapeutic review. $\mathcal{F}$ Neural Transm Gen Sect 1992;38: 91-104.

16 Stell R, Thompson PD, Marsden CD. Botulinum toxin in spasmodic torticollis $\mathcal{f}$ Neurol Neurosurg Psychiatry 1988; 51:920-3.

17 D'Costa DF, Abbott RJ. Low dose botulinum toxin in spasmodic torticollis $\mathcal{F} R$ Soc Med 1991;84:650-1.

18 Lees AJ, Turjanski N, Rivest J, Whurr R, Lorch M, Brookes G. Treatment of cervical dystonia, hand spasms and laryngeal dystonia with botulinum toxin. F Neurol 1992;239:1-4.

19 Poewe W, Wissel J. Experience with botulinum toxin in cervical dystonia. In: Joseph Jankovic, Mark Hallett, eds. Therapy with botulinum toxin. New York: Marcel Dekker, 1994:267-78.

20 Borodic GE, Ferrante R, Pearce LB, Smith K. Histologic assessment of dose-related diffusion and muscle fiber response after therapeutic botulinum-A-toxin injection. Mov Disord 1994;9:31-9.

21 Comella CL, Tanner CM, DeFoor-Hill L, Smith CS. Dysphagia after toxin treatment of spasmodic trorticollis. Neurology 1990;(suppl 1):40:382.

22 Whurr R, Kingsley D, Massarei A. The incidence and nature of dysphagia in patients with spasmodic torticollis (ST) treated with botulinum injections. Mov Disord 1995;10:388.

23 Bhatia KP, Whurr R, Pramstaller PP, Marsden CD. A prospective investigation of the incidence of dysphagia in patients with spasmodic torticollis treated with botulinum toxin injections. Mov Disord 1995;10:388. 